\title{
Contemplating Knudsen's Baseline: Where Small is not so Beautiful
}

\section{Colin Jones, University of Tasmania}

\begin{abstract}
Does the Internet's World Wide Web (the web) represent an opportunity or threat to the small firms of the world? In line with recent calls for entrepreneurship research to adopt a more evolutionary approach, this article considers the context, process, and possible outcomes of small place-based firms operating in a webimpacted environment. Despite initial optimism that the web would provide a level-playing field for firms of all sizes, little evidence exists to support such a notion. When the learning abilities deemed necessary to exploit the web are considered, it would seem that only the most entrepreneurial of small firms would likely adapt to webimpacted environments. It is concluded that the present rate of web-based change represents a unique and valuable research opportunity for entrepreneurship researchers.
\end{abstract}

SOMMAIRE. Le Web représente-t-il une opportunité ou bien une menace pour les petites entreprises du monde entier? Faisant suite à de récentes demandes pour que la recherche en entrepreneuriat adopte une démarche plus évolutionnaire, le présent article considère le contexte, le processus et les résultats possibles de petites entreprises locales opérant dans un environnement affecté par le Web. Malgré un optimisme de départ qui croyait que le Web fournirait aux entreprises de toutes tailles un champ d'action illimité, il faut se rendre à l'évidence qu'il n'en est rien. Quand on considère les aptitudes à apprendre qui sont nécessaires pour exploiter le Web, il semblerait que seules les petites entreprises les plus entrepreneuriales sont susceptibles de s'adapter aux environnements touchés par le Web. On en conclut que le rythme actuel de changement basé sur le Web représente une opportunité de recherche unique et précieuse pour les chercheurs en entrepreneuriat.

\section{Introduction}

The Internet's World Wide Web (the web) is an economic force not unlike other developments that have reshaped the business landscape. If this statement is true, why does as much confusion as optimism surround its development? This paper argues that it is the nature of the change rather than the process of change that is of most importance. Using evolutionary theory as a lens to contemplate the web's epoch and consider past economic transformations, this paper paints a potentially bleak picture for many small firms of today, specifically for small, place-based firms operating in web-impacted environments. Small, place-based firms are defined as established firms whose operations have historically been determined by and confined to a specific geographical location (Jones and Hecker, 2003). Jones and Hecker define a web-impacted environment as being an environment characterized by new innovative Internet-based entrants who use the web's technologies to provide unprecedented and unique consumer value. Therefore, and importantly, the contextual focus of this paper is these small firms, typically with less than 20 employees and operating in either product or service markets.

What makes the issue of small firm exploitation of the web important? The majority of small firms as opposed to large ones (Bjerke and Hultman, 2002) throughout economies the world over, and their contribution to job creation (Birch, 1987) is well recognised. However, despite optimism that the web brought forward a more level playing field (Poon and Swatman, 1997) for entrepreneurial small firms to exploit new niche markets (Forster, 2000), little empirical evidence exists to support such early optimism. 
Conversely, growing evidence suggests many small firms in advanced economies have experienced difficulties exploiting the web (Jones, Hecker and Holland, 2003; Van Beveren and Thomson, 2002; Chaston, Badger, Mangles and Sadler-Smith, 2001; Plume, 2001; and Vescovi, 2000). Is it possible that small firms, the guardians of regional economic prosperity, could be replaced by virtual organizations (like Amazon.com) that contribute little to local employment and development? To fully appreciate the context, process, and probable outcomes associated with small place-based firm survival in webimpacted environments, this paper proposes the use of an evolutionary approach given that "evolutionary theory unites in a single coherent framework a concern for entrepreneurial outcomes and the processes and contexts that make them possible. An evolutionary approach aids in consideration of the creation of new organizational structures (variation), the way in which entrepreneurs modify their organizations and use resources to survive in changing environments (adaptation), the circumstances under which such organizational arrangements lead to success and survival (selection), and the way in which successful arrangements tend to be imitated and perpetuated by other entrepreneurs (retention) (Aldrich and Martinez, 2001: 42).

This approach provides a critical view of the variations that support new enterprises and adaptation within web-impacted environments, and the circumstances (both external and internal to the firm) that lead to the selection and retention of new business practices. This view of the changing nature of small firms requires an appreciation of the organizational hierarchies (Baum and Singh, 1994) that support and influence evolutionary change. Attention to the nested nature of multiple levels of analysis (e.g. individual, firm, population of firms, community of populations, and the ecosystem that surrounds them) enables high-level routines associated with the acquisition, assimilation, transformation, and exploitation of external knowledge to be traced and analysed. Consistent with Low and MacMillan's challenge to entrepreneurship researchers to adopt an evolutionary perspective, this paper "seeks to explain and facilitate the role of new enterprise in furthering economic progress.” (1988: 141) Within the context of the discussion thus far, new enterprise is defined as any new form of business activity (Davidsson and Wiklund, 2001).

This article will proceed as follows. First, the current context of social change is discussed with comparisons made to the impact of railways upon American society. Second, the process of change is considered from an evolutionary perspective. Third, with reference to Knudsen's (2002) baseline theory, the impact of Amazon.com on traditional small placed-based book retailers is considered. Fourth, possible outcomes related to the web's impact upon small-placed based firms operating in web-impacted markets are discussed and their implications considered. The concluding remarks serve as an invitation to others to consider investigating the process of change occurring within web-impacted environments, as the process develops.

\section{The Context of Current Social Change}

In between the view of Porter (2001), that the web changes little, and that of Tapscott (2001), who sees no facet of human activity untouched by its influence, the web is silently reshaping the economic landscape. Both authors contribute to a debate that is unfolding unabated by the pressure of prediction. The web is the product of our imaginations, of our past experiences, and of the hunger for knowledge. It is viewed so differently by so many and its future impact is still unknown. It is truly representative of the process of entrepreneurship, the interaction between human nature and the environment from which accurate predictions are not possible. However, similarities seem to be emerging between 
the impact of the railways on American society and that of the developing web on society in general. The nature of change during both periods do not appear simply to be competence-destroying or competence-extending (Tushman and Anderson, 1986). Instead, it would seem that such change could also be considered competence-extending (Aldrich, 1999) for those firms capable of learning about and responding to its specific nature. This comparison is achieved by considering the development of the American railway system as occurring across three specific phases (Jenks, 1944). First, the railway as an idea, second, the railway as a construction enterprise, and third, the railway as a producer of transportation services. From this perspective the web can be conceptualised in three similar phases: the web as an idea (phase one), the web as the creator of new enterprise (phase two), and the web as an active distribution and/or communication channel (phase three).

\section{The Railway and the Web as an Idea}

The term "idea" does not relate to the original design of the steam locomotion any more than it does the development of the Internet, which has been a source of communication for the United States defence force since 1957. It refers to the acceptance by individuals that the technologies associated with the railway and the web could be employed in new and innovative ways. Both the railway and the web were built in advance of traffic on the assumption of future profitability. It was the sanguine disposition of entrepreneurs who promoted the virtues of both. Jenks notes that "the early railway promoter was not only a potential economic agent; he embodied the dream of developing communities, regions, the continent." (1944: 3) Such a description seems apt for the netpreneurs (Morino, 1999) who exploit the connectivity and immediacy of the web. Therefore, it was the acceptance by society of the ideas presented in the form of web-based new enterprise that has initially given shape to the web-impacted environments of today.

\section{The Railway as a Construction Industry, the Web as the Creator of New Enterprise}

The task laying of thousands of miles of railway line was dependent upon securing land, production inputs (iron and lumber), and physical labour. It was the entrepreneur who acquired and coordinated these elements of production, who exploited the acceptance of the railway as an idea. Alternatively, the interaction occurring between the web's technologies, entrepreneurial behavior, and the changing nature of consumer behavior best explains the web's development. The vital ingredient of this nexus is the development of new forms of knowledge, rather than the coordination of existing production factors. Nevertheless, across both periods of time, individuals capable of interpreting the railway or web as an opportunity appear to have been in short supply. While highly optimistic and speculative attitudes surrounded the development of the railway and web, new levels of complexity regarding the running of small firms were also apparent. The progression from railway lines to railway networks introduced new levels of competition through the linking of many small regional economies with larger economies. The average merchants propensity to carry a wide range of goods and operate as a generalist was threatened by newly emerging multi-divisional firms (Langlois, 2003).

The web, it would seem, is having a similar impact on the operating environment of many small firms all over the world. The web threatens to change the nature of accepted business models today (Tapscott, 2001), just as the events surrounding the railway's development greatly influenced the transformation of the size and structure of firms 170 years ago (Chandler, 1990). However, for many small firms operating in regional economies there were positive externalities associated with the construction of the rail- 
ways (Jenks, 1944). The demand for factors of production resulted in the increased flow of wages which in turn increased the demand for consumer goods, widened markets, and increased firm specialization. Likewise, the web has provided substantial savings on communications through the use of e-mail to small regional firms operating beyond their geographic boundaries. However, along with increased information searching capabilities, these forms of value are by and large retained within the firm rather than shared with customers (Jones, Hecker and Holland, 2003). In summary, just as the railway was heavily dependent upon physical resources for its development, the web is dependent upon new knowledge to exploit its connective and interactive properties. So while there has been a change from labour and physical resources to knowledge, the presence of increasing complexity and radical change to accepted business models appears prevalent across both time periods. During this phase, both the railway and web initially brought about economic benefits for small firms. But ultimately, the full impact is only understood when the railway and web are viewed in their final operating state, as this paper will describe in phase three.

\section{The Railway and the Web as Business Media}

For the small placed-based firm, both the railway and web presented a challenge to their status quo. Left ignored, the railway and web constitute a destructive force capable of changing the composition of markets. From a traditional economic perspective, the mechanism of price is considered to have the most influence on market behaviours. Interestingly, Jenks states that "there is no convincing evidence, however, that railways have ever carried freight at lower costs either to shippers or to society than canals or waterways.” (1944: 12) The changing composition of markets was more likely determined by those entrepreneurs who promoted the speed, flexibility, and efficiency of the railways in comparison to shipping, canals, and other existing forms of transport. Little would appear to have changed with consumers taking from the web what improves their life and leaving behind what does not (Wind, Mahajan and Gunther, 2002). Pricing strategies must be value-based, capturing and sharing value unique to the web. Internalised savings from e-mail and reduced information search costs do not constitute unique web value and therefore cannot be easily shared.

In summary, the composition of markets operating in pre-railway (isolated) towns was forever altered by the arrival of the railway. More efficient entrants challenged existing small, inefficient firms leaving those who survived with a narrow niche within which to operate. Does evidence exist that such displacement and population change is also associated with the web? Consider how consumers gather and arrange travel information and bookings. Once the domain of local travel agencies, airlines and large web-based travel agencies are increasingly offering superior services. Those smaller travel agencies that remain appear more and more focused upon local markets, in many cases a far smaller market to contest with, but nevertheless one where their local expertise has value. As this paper will discuss later, the consequences for those small firms involved in the sale of homogeneous products such as books seem bleaker.

\section{The Process of Change}

Does the composition and nature of firms within a given population change through (natural) selection pressures, adaptation, or both processes? While debate within organizational change literature still features extreme positions, this paper adopts the middle ground. This enables both sides of the selection-adaptation argument to be reconciled 
within Knudsen's baseline theory, given that the progress of knowledge through an adaptive process "requires a baseline through which the value of a possible modification can be evaluated.” (2002: 453) What is not taken for granted however, are the learning abilities of place-based firms operating within web-impacted environments. For many small place-based firms, the emerging business landscape may feel more like vu jàdé (Weick, 1993), the opposite of déjà vu, a time in space where they have never been, have no idea what they are doing, and who it is that could help them. As such, the process of change at the firm level is one considered conditional upon misperceptions (Langlois, 1997), and trial-and-error learning (McKelvey, 1994) through which firms attempt to limit the degrees of maladjustment between themselves and their operating environment.

From the perspective of small place-based firms, two specific schools of thought provide useful frameworks to consider small firm learning. First, the adaptive learning perspective, and second, the knowledge development perspective (Aldrich, 1999). These two approaches provide insights into the difficulties faced by many small place-based firms. The first approach employs experiential learning and is common practice within small firms (Carson and Gilmore, 2000). Basically, successful behaviors are repeated and unsuccessful behaviors discarded. The potential downside of such a learning process in uncertain markets is the reinforcement of the known at the expense and ignorance of the unknown (Cohen and Levinthal, 1990). The second approach relies upon creativity and experimentation and is not directly dependent on prior experience and therefore perhaps more suitable for gaining awareness of technological change. It is this second type of behavior that is typically demonstrated by entrepreneurs. While effective entrepreneurs are considered to be exceptional learners (Smilor, 1997), the distribution of effective (innovative) entrepreneurs in any given population of firms is typically low. Aldrich and Kenworthy (1999) note that overwhelmingly new firms are created through imitation rather than innovation. They observe the tendency of most entrepreneurs to conform to social pressures rather than disobey such pressures through experimentation, creativity, and other challenging behaviors.

Clearly, it should not be taken for granted that all small firm owners have the same capacity to interpret the change and uncertainty associated with web-impacted environments. However, learning must occur in order to maintain (or increase) the firm's fitness vis-à-vis its operating environment. While it is likely that small firms will conduct many different forms and combinations of learning, what matters most is the development and preservation of a fit between the firm's marketplace offerings and the operating environment. To do so, the firm is reliant upon a stock of working knowledge that represents its history, habits, routines, competencies, and market positioning. Davenport and Prusak define a firm's working knowledge as:

a fluid mix of framed experience, values, contextual information, and expert insight that provides a framework for incorporating new experiences and information. It originates and is applied in the minds of knowers. In organizations, it often becomes embedded not only in documents or repositories but also in organizational routines, processes, practices, and norms. (1998: 5)

This suggests that knowledge simultaneously resides not only within individuals but also within the firm and its activities. As such, small firm learning is seen as an interactive process occurring across entities (individuals, routines, firms, populations of firms, and the operating environment) that is governed by specific events (start-up and adaptation) and subsumed within the evolutionary processes of variation, selection, and reten- 
tion. However, it should be noted that codification (documentation) of the owner's tacit knowledge is not taken for granted due to the firm's probable simple operating structures and the high costs codification likely incurs (Snowden, 2002). Knowledge management typically assumes the articulation of tacit knowledge (within the firm) to facilitate its internalisation and conversion into explicit knowledge (Nonaka and Takeuchi, 1995). However, within small, place-based firms, it is proposed that it is the flow of knowledge across entities rather than the management of specific knowledge content that most determines a firm's working knowledge.

The following discussion highlights the probable inseparability of the small firm owner's disposition towards learning from that of the small firm's ability to learn. As will be further discussed, the pressure of natural selection upon the firm's marketplace offerings equally reflects the selection pressure on the owner's "habits of thought" (Veblen, 1925: 191). As such, through attention to the firm's routines (and sub-routines) that support the firm's learning capabilities, the probable consequences of such habits emerge. Ultimately, this suggests that for the small place-based firm embedded in a web-impacted environment, it is through selection of the fittest (and most adaptive) temperaments that new enterprise activities emerge as favoured variations. At the extreme ends of a continuum, individual habits representing indifference and curiosity are proposed to best illustrate the small place-based firm's approach to learning within web-impacted environments. Each end point is tethered by opposing evolutionary positions. Indifference leads to the preservation (retention) of the status quo and therefore little active consideration of new external knowledge, whereas, a tendency towards curiosity leads to an increased awareness of, and alternative ways of thinking about marketplace variations, a necessary precondition of adaptive evolution (Pfeffer, 1982). In line with Aldrich and Kenworthy, it is the reproducer's conformity to social norms that produces an indifference to learning outside the accepted way of production. (1999: 25) In contrast, it is innovators who "disobey ingrained cultural routines, norms, and habits" to speculate about alternative variations to the accepted way of production.

At any given time, a firm's relative fitness should provide feedback that guides the nature of future operations. However, despite assumptions that unprofitable firms will be efficiently selected from their operating environment (Murmann, 2003), markets are in fact "quite tolerant to underperformance" (Whittington, 1993: 24). A failing of the current literature is its reluctance to explicitly identify what is being selected. Unprofitable firms seems sensible, however it doesn't allow an understanding of the processes and events that led to or maintained the state of unprofitability. What is obvious is that specific elements of the firm's performance have caused insufficient profits. Therefore, a focus is required upon the elements of the firm's activities that interact with the operating environment. What must be considered is the actual nature of what is offered for consumption and how the firm receives and interprets feedback from such interaction.

It is proposed that what constitutes the firm's offerings could be considered a combination of activities that are delivered by humans and technologies, actual products and services, and the identity of the firm. These three elements, while not representing an exhaustive search for all possible offerings, provide elements of focus. As illustrated in Figure 1, feedback is assumed to be always possible from the interacting elements of the firm's performance. However, any such feedback is balanced against the existing perceptions and marketplace knowledge held within the firm's stock of working knowledge. It is suggested that modification to existing goals, boundaries, and activities occurs through 


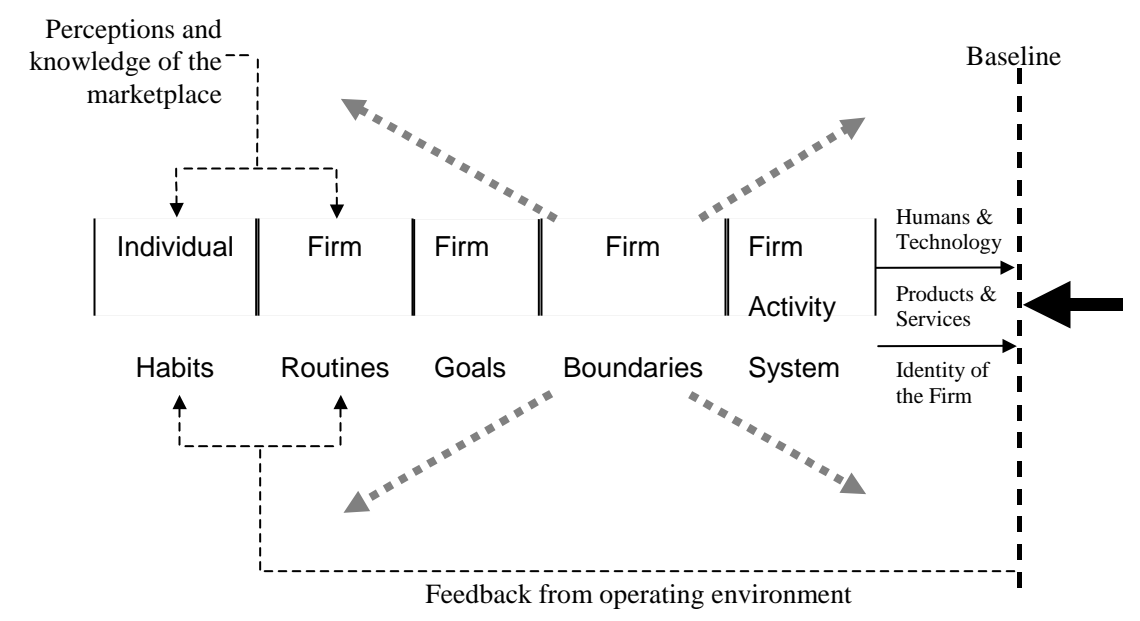

Figure 1. The processes of firm-environment interaction.

a process of trial-and-error learning that is largely governed by the individual habits and organizational routines present within the firm.

The firm's three interacting elements are now briefly considered in more detail. While the combinations of activities that are delivered by humans and technologies seem broad in description, there can be a more specific consideration. This first element relates to all contact points through which the firm and its agents interact with all external stakeholder groups. The actual services and products the firm provides should require no further explanation as an element through which firm/stakeholder interaction occurs. The last proposed element is that of identity. Identity has previously been considered an interactor with regards to "the personal and professional identity of team members." (Knudsen, 2002: 461) However, the proposed role of identity considered here is at the higher level of the firm itself. The literature tends to use the phrase "corporate identity" (Stuart, 1997) to describe corporate personality, which is based upon corporate strategy. Here, the term corporate will be used interchangeably with firm to reflect the broad application of the evolutionary ideas expressed. The identity of a firm embodies its culture and personality. Therefore, a function of its interaction with external stakeholders is the firm's image. This image influences the firm's fitness within its operating environment.

\section{Learning and Ignorance}

When considering the learning capabilities of small place-based firms, the absence of a universal explanation of small firm learning must be acknowledged. It should also be recognised that few technology linkers may exist to help small place-based firms make sense of how to adapt to the web (Jones, Hecker and Holland, 2003). As previously discussed, a formal explanation of how and why small place-based firms may or may not adapt to web-impacted environments is difficult. However, the reconceptualisation of the absorptive capacity construct by Zahra and George (2002) does provide a mechanism through which the appropriate learning behaviors can be discussed. Since the seminal contribution of Cohen and Levinthal (1990), absorptive capacity has been associated with the acquisition and use of knowledge to enhance firm performance through increased learning and innovation (Kim, 1998; Liu and White, 1997; Keller, 1996). Cohen and Levinthal 
define absorptive capacity as the "ability to recognize the value of new information, assimilate it, and apply it to commercial ends.” (1990: 128) Originally operationalised as a single factor component with three dimensions (valuing, assimilating, and applying new knowledge), the potential influence of absorptive capacity was understood to be dependent upon the firm's prior knowledge base and skills.

However, in their reconceptualisation, Zahra and George define absorptive capacity as having two distinct components that together are operationalized as "a set of organizational routines and processes by which firms acquire, assimilate, transform, and exploit knowledge to produce a dynamic organizational capability.” (2002: 186). When considered from an evolutionary point of view, absorptive capacity theory highlights critical activities that would greatly influence small place-based firm adaptation in web-impacted environments. It also provides a complementary framework for considering the learning process within small place-based firms given that the construct can be operationalised within individuals and firms. Absorptive capacity theory identifies knowledge development capabilities and deficiencies similar to the generic evolutionary processes "of variation, selection, retention and struggle that jointly produce patterned changing in evolving systems.” (Aldrich, 1999: 2)

Within this new definition are two specific components: potential (acquisition and assimilation) and realised (transformation and exploitation) absorptive capacity. Potential absorptive capacity is the capability to sense what information is relevant, acquire it, analyse it, comprehend it, and internalise it. As such, it provides the firm with an appreciation of the exogenous environmental forces that may or may not favour the firm's existing offerings. Realised absorptive capacity relates to the processes that blend existing knowledge with newly acquired knowledge to gain new insights to opportunities or problems and provide structured pathways to develop new competencies. Together, the two components' potential provides the foundation of "a dynamic capability pertaining to knowledge creation and utilization.” (Zahra and George, 2002: 185) When viewed from an evolutionary perspective, it is argued that this interpretation of the absorptive capacity construct supports discussion of how, why, and when individual firms learn about environmental change.

The four dimensions of absorptive capacity-acquisition, assimilation, transformation, and exploitation - are related to individual habits and organisational routines or potential future behaviours. These potential capabilities are triggered by external or internal events that cause to the firm to respond to the stimuli. That is, the firm's ability to efficiently acquire and assimilate external knowledge is a function of their past capability to perform such behaviours under the same context and selective pressures. However, this learning potential only influences the firm's ability to maintain or increase its fitness if all four dimensions coexist as a cohesive whole. Merely increasing awareness of variations does not endow the firm with the ability to maintain or increase the fitness of its interacting phenotypic elements. Thus, the firm is subject to external selection forces at two specific levels. First, the elements that interact face the pressures of natural selection, and ultimately, this interaction results in the differential selection of the habits or routines responsible for replicating processes within the firm. Given that firms can acquire new characteristics from the marketplace, the firm's degree of potential absorptive capacity becomes critical to the process of adapting to market shocks and exploiting opportunities. Importantly, this capability is mediated by the degree of prior knowledge held across specific domains. 
Campbell states that if all components of the variation-selection-retention process are present, then "a socio-cultural learning process is inevitable." (1965: 27) Clearly, the value of the absorptive capacity construct relies upon a process dependent upon all three evolutionary components to successfully act as an effective learning mechanism. Learning is defined within an organizational setting as, outcomes related to change via analysis or imitation or a process of adaptation dependent upon delicately balancing exploration against exploitation (March, 1991). This suggests that to achieve optimal learning dependent outcomes, both variation and retention processes must relate to each, despite the inherent forces that alienate each from the other. The ability of firms to select new variations (or retain existing variations) clearly shapes the nature of the firm's interaction. However, to use an adaptation of Aristotle's approach to the use of anger, any firm can change. That is easy. But to change the right activity systems, to the right degree, at the right time, for the right purpose, and in the right way is not easy. This paper will explore this point further by briefly considering the emergence of Amazon.com with reference to Knudsen's (2002) baseline idea.

\section{The Invisibility of Amazon.com}

Knudsen (2002) has proposed the existence of a baseline (see Figure 1) through which the firm's adaptive behaviours can be reconciled against the process of natural selection. From this perspective, the process of Lamarckian ${ }^{1}$ evolution can be seen as guided by the awareness of external pressures associated with the interaction the firm's activities, products and services, and identity have with the environment. Hodgson (2003) and Knudsen (2001) assert that both the Lamarckian and natural selection processes share a common Darwinian causal structure. However, the processes are not of equal strength, given the relative position of any individual typical firm vis-à-vis its operating environment. That is, while the firm's interacting elements can be altered via Lamarckian evolution, natural selection provides the final judgement on the fitness of the routines with respect to the operating environment. Therefore, it is logical that repeated successful adaptive behaviours are able to be reconciled against a baseline that limits the degree of change. Unlike previous forms of directly observable competition, the nature of Amazon.com's webbased business model variations that are increasingly favoured by many consumers remain largely unobservable to most small place-based booksellers. Consequently, increased complexity of learning (McKelvey, 1994) may result in firms struggling to acquire, comprehend and implement knowledge associated with such newly favoured routines and competencies. Barriers may exist through geography such as an inability to adequately observe the operations of marketspace firms, and through legalities such as Amazon.com's patented one-click payment system.

Without access to know-how knowledge (information necessary to fully exploit the web) and principles knowledge (information relating to the web's theoretical underpinnings), as Rogers (1995) asserts, the small place-based firm is potentially locked out of a new technological paradigm (Dosi, 1984). Such barriers decrease exposure to variations and prolong the maladjustment thereby restricting the firm's ability to adapt. This is because the firm must bridge the knowledge gap between what is known and what is not through foreign knowledge bases that are difficult to acquire and assimilate, and therefore

1. The term Lamarckian evolution is used in a metaphorical sense (Hull, 1984) given that it is acknowledged that a direct analogy for the genotype-phenotype does not exist to explain the process sociocultural learning. 
difficult to transform and exploit. It is also possible that routines imprinted into firms prior to the emergence of the web may not support the learning behaviors required to adapt to the web (Tucker, Singh and Meinhard, 1990). Under such circumstances the web, despite being a source of new variation and a catalyst to altering the existing selection criteria (Aldrich, 1999), may also pose a threat to survival.

With reference again to Figure 1, the firm's activity systems represent behaviours that produce products and services are responsible for the development of a firm's identity and facilitate contact between the firm's systems (be they human or technological) and external stakeholders. In short, they are responsible for the firm's marketplace offering. At anytime, the firm is in receipt of feedback from its stakeholders. The market share achieved by products and services, the image present in the marketplace of the firm, and information received during contact between the staff and/or technological interface all represent substantial and ongoing feedback. This feedback should act to stimulate further planning, revision, and implementation of future performance. The adaptive firm tentatively alters the elements of its interaction based on its appreciation of the imaginary baseline through which the firm's performance is balanced against the forces of natural selection.

However, within web-impacted environments, Knudsen's (2002) baseline theory is problematic. While it is logical that repeated successful adaptive behaviours are able to be reconciled against a baseline that limits the degree of change, the problem of evaluating a changing baseline against a rapidly changing environment introduces limitations. Under such conditions, it is challenging to envisage how a meaningful evaluation of positive or negative outcomes associated with internally driven change could occur. Given that the firms of today represent some form of adaptation to "past circumstances, and are therefore never in full accord with the requirements of the present” (Veblen, 1925: 191), the challenge of survival depends upon the minimisation of the maladjustment between firm's interacting elements (its activities, products and services, and identity) and the operating environment. Clearly, the firm's learning capabilities are critical to enabling continual safe passage through the environment's corridor of fitness. The "corridor of fitness" concept (Jones, 2004) refers to the degrees of freedom afforded to the firm's activities, products and services, and identity by the operating environment. The proposition being that no identifiable equilibrium position exists (or is possible in reality), but rather that the relative degree of environmental stability determines the breadth of a buffer zone within which degrees of fitness are achieved. Bruderer and Singh (1996) suggest that instead of assuming an (either/or) equilibrium position exists, firms are guided by continual feedback through which they adjust their interacting elements to achieve a higher degree of organizational fitness. Thus, they tend to be located to either side of a hypothetical, and every changing equilibrium position that is akin to the Holy Grail. Marketplace feedback provides the guidance to the adaptive behaviours of the firm. Therefore the process of internal selection, a function of the habits and routines present within the firm, is ultimately judged by acceptance of the firm's interacting elements by external stakeholders.

What emerges from this discussion is the need for the habits and routines of the firm to have the potential to act in harmony throughout all four behavioural dimensions of the absorptive capacity construct. The efficiency between exploration and exploitation is determined by the nature of the habits and routines that initially support the acquisition and assimilation of external knowledge and then the transformation and exploitation of knowledge. Such continuity of potential behaviours is crucial given that the process of socio-economic evolution is dependent upon the interplay between interacting and replicating enti- 
ties (Baum and Singh, 1994). Working against this desirable process are internal and external forces that differentially influence the development of potential absorptive capacity and the realised absorptive capacity. Given that the realised absorptive capacity is the primary source of adaptive improvements (Zahra and George, 2002), it is clearly important to consider impediments to the cumulative process that enables exploration and subsequent exploitation. Returning to the example of Amazon.com, the implications for small placebased bookshops can be further explored through consideration of the possible outcomes associated with the emergence of one of the world's most recognisable brands.

\section{Thinking About Outcomes}

While it is unlikely that any owner is either only indifferent or only curious about change in the operating environment, the discussion follows this path to emphasis suboptimal learning processes that may bypass a baseline approach. Through recognising the shortcomings of such learning processes, a clearer notion of what processes would support optimal learning in web-impacted environments becomes more evident. Just "as a dark background is required for exhibiting the brightness of a picture” (James, 1880: 442), so do sub-optimal learning processes highlight the learning processes that increase a firm's adaptive capabilities. However, a paradox regarding the necessity of both indifference and curiosity exists. It is proposed that optimal learning processes are a function of the abilities of the owner(s), and therefore the firm, to maintain a shifting balance between both indifference and curiosity to facilitate the evolutionary process of variation, selection, and retention.

Regardless of whether the owner's habits of thought result in a disposition towards indifference or curiosity, they nevertheless introduce degrees of efficiency that significantly influence the process of learning. At either end of the continuum, stable habits engender efficiency (Postrel and Rumelt, 1996) into the owner's day-to-day activities. However, the blocking out effect of such efficiency creates two potentially disastrous learning pathways for the small place-based firm. Habitual indifference to learning about the changing operating environment will most likely result in the retention of existing routines without consideration of their future suitability. Under such circumstances, it is the exploitation of existing operating routines that dominate. Alternatively, habitual curiosity may have the opposite effect, with firms extremely efficient at acquiring information relating to other possible means of production but unable to determine how to best produce their goods or services. The argument presented is that it is the firm's degree of absorptive capacity that mediates the influence of both dispositions. The importance of the owner's disposition and the issue of efficiency are illustrated through the three following propositions:

P1: During times of change, an indifference to market feedback eventually reduces the value of internal efficiency.

Many firms may be indifferent to learning about events external to their operating sphere. The web is considered perhaps a passing fad, a waste of valuable time, and the focus is upon the replication and improvement of existing systems and structures. Learning within this context is driven by the desire to more efficiently produce the firm's existing interacting elements. However, while the firm's competencies in certain areas may increase, their access to other areas of experience and knowledge is likely to decrease (Levinthal, 1997). Therefore, the firm's boundaries act to limit the extent of learning and reduce awareness of marketplace variations. The potential significance of the likes of 
Amazon.com may not alter the deeply entrenched mental models that act to prevent appreciation of what is occurring outside the firm. The danger for such firms, reliant upon experiential learning, is that they may only address the nature of change in their operating environment "only tardily and reluctantly, and only under coercion exercised by a situation which has made the accredited views untenable" (Veblen, 1925: 192). That is, the degree of maladjustment has become apparent to the firm's owner with the web viewed as a threat, rather than an opportunity. Given a likely increased complexity of learning (McKelvey, 1994) surrounding the processes that support and comprise the interacting elements of Amazon.com, these firms are likely to fail to acquire, comprehend, and therefore implement the external knowledge associated with online booksellers. They are at the mercy of the pressures of natural selection with the efficiency of their internal processes tested by a shifting fitness landscape.

P2: During times of change, curiosity of change in the operating environment variations does not prevent fatal misperceptions of the firm's operations or market.

Without the ability to fully comprehend and integrate the acquired external knowledge, the value of the entrepreneur's heuristic-based logic (Alvarez and Busenitz, 2001) to simplify environmental uncertainty is lost. Langlois (1997) suggests that it is possible two forms of misperception may occur. First, an inability to exploit changing conditions by gaining or improving existing core competences (operational misperception), and second, the firm's inability to apply existing competencies in a way that creates value (market misperception). Again, the value of Knudsen's (2002) baseline within the Figure 1 becomes more evident. While the firm's interacting elements can be altered in response to perceived change in the operating environment, ultimately, natural selection provides the final judgement on the fitness of the firm's interacting elements (and therefore the owner's habits and the firm's routines) vis-à-vis their fitness within the business landscape.

Change is not a synonym for progress, but rather a process largely constrained by the past. In accepting the assumption that the firm's learning capabilities and its owner's cognitive abilities are relatively inseparable, mere curiosity and awareness alone are not enough to support the change process. The development and maintenance of a dynamic capability requires both potential and realised absorptive capacity. The owner's disposition may appear entrepreneurial, but he or she must be proficient at analytical problem solving to develop new knowledge. In the absence of new knowledge, exploitation of technological (or non-technological) opportunities within in web-impacted environments is limited by the technological paradigm (Dosi, 1984) within the firm that governs the normal patterns of problem solving or opportunity exploration.

P3: During times of change, balancing the efficiency of indifference and curiosity is necessary to optimally alter the interacting elements of the firm.

In web-impacted environments, firms must not be solely preoccupied with the efficiency of day-to-day operations or optimistically entertaining all manner of possible changes to the status quo. Entrepreneurs must learn from all experiences, sense the pulse of the customer (Smilor, 1997), and use their foresight to discover new opportunities. The firm's interacting elements must be altered through a process that encapsulates the entire evolutionary process, a learning process through which the small place-based firm acts with consideration of what is internally possible balanced against what is externally desirable. Realised absorptive capacity must be present to enable existing knowledge to be integrated with relevant external knowledge. However, given the propensity of many 
small firm owners to work in and not on their business (Gerber, 1995), it is plausible that the learning behaviors associated with P1 and P2 may be more frequent than those suggested in P3.

\section{Conclusion}

The plight of the small place-based firm operating in web-impacted environments has been discussed. When consideration is given to the change occurring in the social setting of these firms, comparisons can be drawn to the change introduced by the railways within America. It has been suggested that the carrying capacity of many industries influenced by the web will be altered. Many firms that remain are likely to do so through a focus on a new or narrower niche. Also, that the transformation of a firm's operations and interacting elements will be dependent upon their learning capabilities given that "learning is a key process that distinguishes technological innovation as a game of chance from one that is a game that involves skill as well” (Garud, Nayyar and Shapira, 1997, p. 7). Without learning, the adaptive prospects of the small place-based firm are determined predominately by the forces of natural selection. Acknowledgement of learning processes admits the presence of Lamarckian evolution through which an attempt is made by the firm to adjust its interacting elements in response to macro forces.

With reference to Knudsen's (2002) baseline idea, this paper suggests that many small firms may have inadequate learning skills to directly respond to the changing nature of their operating environment. A paradigm shift has arrived that has a potential to surpass the change introduced by the railways 170 years ago. The web's connectivity has made it possible for the likes of Amazon.com to simultaneously reshape the nature of natural selection forces in local, national, and international markets. This paper explicitly identifies elements of interaction that form specific areas of focus for future research. This represents an invitation to others interested in exploring the web's "primordial organizational soup ... to study the dynamics of entrepreneurship and the social construction organizational, population, interpopulation, and community-level dynamics" (Aldrich and Baker, 2001: 235). The interacting elements thus provide a window through which to observe a learning process that may or may not provide reconciliation of the behaviours related to internal change against the forces of external change. Such research contributes to the field of entrepreneurship by examining the learning processes through which market opportunities are discovered (or ignored) and subsequently exploited, a critical issue in entrepreneurship theory (Alvarez and Barney, 2002).

Given that the routines associated with the four dimensions of absorptive capacity are embedded within firm processes, research performed from within the firm is expected to be more revealing than that done from outside (Rouse and Daellenbach, 1999). Therefore, to go inside Knudsen's (2002) baseline, a dual methodology comprising real-time longitudinal case studies with multiple retrospective case studies (Leonard-Barton, 1995) would provide access to age, period, and cohort effects (Aldrich, 1999). Such an approach would support the identification of historical patterns of organizational change within a selected industry and an intimate view of those same patterns evolving in real-time. This would enable an understanding of the historical context surrounding the learning behaviors of small place-based firms prior to and after encountering a web-impacted environment. As such, the important issue of which factors determine the ascendancy of either adaptive or selection forces (Amburgey and Singh, 2002) and the confirmation of the noted interaction elements (and identification of any others elements) are potential research outcomes. 


\section{Contact Information}

For further information on this article, contact

Colin Jones, Faculty of Commerce, University of Tasmania, Private Bag 16, Hobart TAS 7001 Australia.

Phone: +61 362262826

Fax: +61 362262808

Email: Colin.Jones@utas.edu.au

\section{References}

Aldrich, H.E. 1999. Organizations Evolving. London: Sage Publications.

Aldrich, H.E. and T. Baker. 2001. "Learning and Legitimacy: Entrepreneurial Responses to Constraints on the Emergence of New Populations and Organizations.” Pp. 207-35 in C.B. Schoonhoven and E. Romanelli (eds.), The Entrepreneurship Dynamic: Origins of Entrepreneurship and the Evolution of Industries. California: Stanford University Press.

Aldrich, H.E. and A.L. Kenworthy. 1999. "The Accidental Entrepreneur: Campellian Antinomies and Organizational Foundings.” Pp. 19-34 in J.A.C. Baum, and B. McKelvey (eds.), Variations in Organization Science: In Honor of Donald T. Campbell. London: Sage Publications.

Aldrich, H.E. and M.A. Martinez. 2001. "Many are Called, but Few are Chosen: An Evolutionary Perspective of the Study of Entrepreneurship," Entrepreneurship Theory and Practice 25, no. 4: 41-56.

Alvarez, S.A. and J.B. Barney. 2002. "Resource-Based Theory and the Entrepreneurial Firm.” Pp. 89-105 in M.A. Hitt, R.D. Ireland, S.M. Camp and D.L. Sexton (eds.), Strategic Entrepreneurship: Creating a New Mindset. Cornwall: Blackwell Publishing.

Alvarez, S.A. and L.W. Busenitz. 2001. "The Entrepreneurship of Resource-Based Theory,” Journal of Management 27, no. 6: 755-75.

Amburgey, T.L. and J.V. Singh. 2002. “Organizational Evolution.” Pp. 327-43 in J.A.C. Baum (ed.), The Blackwell Companion to Organizations. Oxford: Blackwell Publishers.

Baum, J.A.C. and J.V. Singh. 1994, "Organizational Hierarchies and Evolutionary Processes: Some Reflections on a Theory of Organizational Evolution.” Pp. 3-20 in J.A.C. Baum and J.V. Singh (eds.), Evolutionary Dynamics of Organizations. New York: Oxford University Press.

Birch, D. 1987. Job Creation in America: How Our Smallest Companies Put the Most People to Work. New York: Free Press.

Bjerke, B. and C. Hultman. 2002. Entrepreneurial Marketing: The Growth of Small Firms in the New Economic Era. Cheltenham: Edward Elgar.

Bruderer, E. and J.T. Singh. 1996. "Organizational Evolution, Learning, and Selection: A Genetic-AlgorithmBased Model,” Academy of Management Journal 39, no. 5: 1322-49.

Campbell, D.T. 1965. "Variation and Selective Retention in Socio-Cultural Evolution.” Pp. 19-49 in H.R. Barringer, G.I. Blanksten and R.W. Mack (eds.), Social Change in Developing Areas: A Reinterpretation of Evolutionary Theory. Cambridge: Schenkman Publishing.

Carson, D. and A. Gilmore. 2000. “Marketing at the Interface: Not What but How.” Journal of Marketing Theory and Practice 8, no. 2: 1-7.

Chandler, A.D. 1990. Scale and Scope: The Dynamics of Industrial Capitalism. Cambridge: The Belknap Press.

Cohen, W.M. and D.A. Levinthal. 1990. "Absorptive Capacity: A New Perspective on Learning and Innovation," Administrative Science Quarterly 35 (March): 128-52.

Davenport, T.H. and L. Prusak. 1998. Working Knowledge: How Organizations Manage What They Know. Boston, MA: Harvard Business School Press.

Davidsson, P. and J. Wiklund. 2001. "Levels of Analysis in Entrepreneurship Research: Current Research Practice and Suggestions for the Future," Entrepreneurship Theory and Practice 25, no. 4: 81-99.

Dosi, G. 1984. Technical Change and Industrial Transformation. Hong Kong: MacMillin Press.

Forster, N. 2000. "The Potential Impact of Third Wave Technolgies on Organistions," Leadership and Organisational Development 21, no.5: 254-62.

Garud, R., P.R. Nayyar and Z.B. Shapira. 1997. Technological Innovation: Oversights and Foresights. Melbourne: Cambridge University Press.

Gerber, M.E. 1995. The E Myth Revisited: Why Most Small Business Don't Work and What to Do About It. New York: HarperCollins Publishers.

Hodgson, G.M. 2003. "The Mystery of the Routine: The Darwinian Destiny of an Evolutionary Theory of Economic Change," Revue Economique 54, no 2: 355-84. 
Hull, D. 1984. “Lamarck Among the Anglos.” Pp. xl-lxvi in J.B. Lamarck (ed.), Zoological Philosophy: An Exposition with Regards to the Natural History of Animals. Chicago: University of Chicago Press.

James, W. 1880. “Great Men, Great Thoughts, and the Environment,” The Atlantic Monthly 46 (October): 441-59. Jenks, L.H. 1944. "Railroads as an Economic Force in American Development," The Journal of Economic History 4, no. 1: 1-20.

Jones, C. 2004. “Towards a Unified Darwinian Explanation of Firm Transformation.” Paper presented at the 6th International Conference on the Dynamics of Strategy, Surrey, UK, June.

Jones, C. and R. Hecker. 2003. "Invisible Opportunities and Irreversible Trends,” Journal of New Business Ideas and Trends 1, no.1: 38-49.

Jones, C., R. Hecker and P. Holland. 2003. "Small Firm Internet Adoption: Opportunities Forgone, a Journey not Begun,” Journal of Small Business and Enterprise Development 10, no. 3: 287-97.

Keller, W. 1996. "Absorptive Capacity: On the Creation and Acquisition of Technology in Development," Journal of Developmental Economics 49, no 1: 199-210.

Kim, L. 1998. "Crisis Construction and Organizational Learning: Capability Learning in Catching-Up at Hyundai Motor," Organization Science 9, no. 4: 506-21.

Knudsen, T. 2001. "Nesting Lamarckism with Darwinian Explanations: Necessity in Economics and Possibility in Biology.” Pp. 121-59 in J. Laurent and J. Nightingale (eds.), Darwinism and Evolutionary Economics. Northampton, MA: Edward Elgar Publishing.

—. 2002. "Economic Selection Theory,” Journal of Evolutionary Economics 12, no. 4: 443-70.

Langlois, R.N. 1997. "Cognition and Capabilities: Opportunities Seized and Missed in the History of the Computer Industry.” Pp. 71-94 in R. Garud, P. Nayyar and Z. Shapira (eds.), Technological Innovation. New York: Cambridge University Press.

—. 2003. "The Vanishing Hand: The Changing Dynamics of Industrial Capitalism,” Industrial and Corporate Change 12, no. 2: 351-85.

Leonard-Barton, D. 1995. “A Dual Methodology for Case Studies: Synergistic use of a Longitudinal Single Site with Replicated Multiple Sites.” Pp. 38-64 in G.P. Huber and A.H. Van de Ven (eds.), Longitudinal Field Research Methods: Studying Processes of Organizational Change. London: Sage Publications.

Levinthal, D. 1997. "Three Faces of Organizational Learning: Wisdom, Inertia, and Discovery.” Pp. 167-80 in R. Garud, P.R. Nayyar and Z.B. Shapira (eds.), Technological Innovation: Oversights and Foresights. Melbourne: Cambridge University Press.

Low, M.B. and I.C. MacMillan. 1988. "Entrepreneurship: Past Research and Future Challenges,” Journal of Management 14, no. 2: 139-61.

Liu, X. and R.S. White. 1997. "The Relative Contributions of Foreign Technology and Domestic Inputs to Innovation in Chinese Manufacturing Industries," Technovation 17, no. 3: 119-25.

McKelvey, B. 1994. "Evolution and Organizational Science.” Pp. 314-26 in J.A.C. Baum and J.V. Singh (eds.), Evolutionary Dynamics of

Organizations. New York: Oxford University Press.

March, J.G. 1991. "Exploration and Exploitation in Organizational Learning," Organization Science 2, no.1: 71-87.

Morino, M. 1999. “Netpreneurs: A New Breed of Entrepreneur.” Kauffman Center for Entrepreneurial Leadership. C19992487. http://www.score.org/eb_18.html. Accessed on 14/10/2003.

Murmann, J.P. 2003. Knowledge and Competitive Advantage. New York: Cambridge University Press.

Nonaka, I. and H. Takeuchi. 1995. The Knowledge-Creating Company: How Japanese Companies Create the Dynamics of Innovation. New York: Oxford University Press.

Pfeffer, J. 1982. Organizations and Organization Theory. Melbourne: Pitman.

Plume, H. 2001. "Survival of the e-Fittest." http://www.capcollege.bc.ca/admin/Formedia/2001releases/ ebiz.html. Accessed on 5/8/2001.

Poon, S., and P.M.C. Swatman. 1997. "Small Business use of the Internet: Findings From Australian Case Studies," International Marketing Review 14, no. 5: 385-402.

Porter, M.E. 2001. "Strategy and the Internet," Harvard Business Review 79, March: 63-79.

Postrel, S. and R.P. Rumelt. 1996. "Incentives, Routines and Self-Command.” Pp. 72-102 in G. Dosi and F. Malerba (eds.), Organization and Strategy in the Evolution of the Enterprise. London: MacMillan Press.

Rogers, E.M. 1995. Diffusion of Innovations (4th ed.). New York: The Free Press.

Rouse, M.J. and U.S. Daellenbach. 1999. "Rethinking Research Methods for the Resource-Based Perspective: Isolating Sources of Sustainable Competitive Advantage,” Strategic Management Journal 20, no. 5: 487-94.

Smilor, R.W. 1997. “Entrepreneurship: Reflections on a Subversive Activity,” Journal of Business Venturing 12, no. 5: 341-46.

Snowden, D. 2002. “Complex Acts of Knowing: Paradox and Descriptive Self-Awareness," Journal of Knowledge Management 6, no. 2: 100-11. 
Stuart, H. 1997. "Exploring the Corporate Identity/Corporate Image Interface: An Empirical Study of Accountancy Firms," Journal of Communication Management 2, no. 4: 357-73.

Tapscott, D. 2001. "Rethinking Strategy in a New Networked World." Strategy + Business 24 (Third Quarter): 1-8. http://www.strategy-business.com/strategy/01304. Accessed on 30/8/2002.

Tucker, D.J., J.V. Singh and A.G. Meinhard. 1990. "Founding Characteristics, Imprinting, and Organizational Change.” Pp. 182-200 in J.V. Singh (ed.), Organizational Evolution: New Directions. London: Sage Publications.

Tushman, M.L. and P. Anderson. 1986. "Technological Discontinuities and Organizational Environments,” Administrative Science Quarterly 31, no. 3: 439-65.

Van Beveren, J. and H. Thomson. 2002. "The Use of Electronic Commerce by SMEs in Victoria, Australia," Journal of Small Business Management 40, no. 3: 250-53.

Veblen, T. 1925. The Theory of the Leisure Class. London: George Allen and Unwin.

Vescovi, T. 2000. "Internet Communication: The Italian SME Case," Corporate Communications: An International Journal 5, no. 2: 107-11.

Weick, K.E. 1993. “The Collapse of Sensemaking in Organizations: The Mann Gulch Disaster,” Administrative Science Quarterly 38, no.4: 628-52.

Whittington, R. 1993. What is Strategy: and Does it Matter. London: Routledge.

Wind, Y., V. Mahajan and R.E. Gunther. 2002. Convergence Marketing. Sydney: Prentice Hall.

Zahra, S.A. and G. George. 2002. "Absorptive Capacity: A Review, Reconceptualization, and Extension,” Academy of Management Review 27, no. 2: 185-203. 